\title{
Curriculum Typology
}

\author{
Rahmatallah Marzooghi ${ }^{1}$ \\ ${ }^{1}$ Associate Professor, Shiraz University, Shiraz, Iran \\ Correspondence: Rahmatallah Marzooghi, Associate Professor, Shiraz University, Shiraz, Iran. E-mail: \\ bakhteeyar@gmail.com
}

Received: June 8, 2016 Accepted: August 17, 2016 Online Published: December 1, 2016

doi:10.5539/ijel.v6n7p166 URL: http://dx.doi.org/10.5539/ijel.v6n7p166

\begin{abstract}
An abstract is a brief and comprehensive summary of the contents of the article. It allows readers to survey the various definitions that have been presented by scholars about the concept of curriculum as a "plan" or "product", and due to the vast variation of definitions, many classifications have been made in regarding them. Since "the curriculum" is not a "type" but has "types" itself, it is not possible to present a comprehensive definition for all those curricula such as intended, implemented, learned, implicit, hidden, sterilized, omitted, neglected, empty, taught, not taught, existed, non-existed, and so on. Therefore each curriculum must be defined based on its own unique type. In this article by using a new and innovative approach, more than 200 types of curricula, based on their common traits, are classified into 16 categories. The analysis and classification which are unique and unexampled in its own nature in the curriculum literature explain some controversies about the definitions and types of curricula categorization.
\end{abstract}

Keywords: typology, classification, curriculum, categorization strategy

\section{Introduction}

During the past decades, much effort has been devoted to defining curriculum. The term curriculum has numerous definitions. Some scholars see the numerous and divers definitions as a problem, while others suggest that when analyzed carefully, these definitions differ little (Cridel, 2010, p. 179). Philip Jackson (1992) offers a clear and straightforward explanation for multiple curriculum definitions in relation to the growth of the curriculum field. For him, new definitions represent efforts to change or embellish the traditional meaning of curriculum as "course of study". Bobbitt (1918) suggested that a curriculum is an entire range of experiences in its broadest sense and that only some of those experiences fall under the auspices of schooling. Further, these experiences outside schools are both directed and undirected in nature. In his analysis of curriculum, Kliebard (1992) expended upon Bobbitt's notions of curriculum by acknowledging undirected curriculum experiences such as the null and hidden curriculum. The idea behind the null curriculum is that schools shape the way students think not only by what they include in the curriculum, but also by what they omit. By hidden curriculum radical scholars mean those attitudes, values, and beliefs that are conveyed to students as part of overall school culture but not explicitly stated in curriculum documents (Null, 2011, p. 93).

When we asked scholars, teacher and students what curriculum means to them, they always indicated that it means the written and intended curriculum. The intended curriculum is the overt curriculum that is acknowledged in policy statements as what schools or others educational institutions or arrangements set out to accomplish. Sometimes the intended curriculum is contrasted with the hidden curriculum, the taught curriculum, the null curriculum, the tested curriculum and the learned curriculum. This beginning definition is a metaphor for what the curriculum has perceived and become in education.

\section{Literature Review}

There are multiple definitions of curriculum from Oliva (1997, p. 4). Curriculum is what is taught in schools, a set of subject, content, a program of studies, a course of study, a set of materials, everything that is planned by school, a series of experiences undergone by learners in a school. Willson (2006) believed that curriculum means anything that teaches a lesson, planned or otherwise. Humans are born learning, thus the learned curriculum actually encompasses a combination of all the hidden, null, written, political and societal. Since students learn all time through exposure and modeled behaviors from their peers, their teachers and so on, a curriculum is considered the "hart" of any learning institutions which means that schools or universities cannot exist without 
curriculum. In its broadest sense, curriculum refers to the total learning experiences of individuals not only in school, but in society as well (Bilbao et al., 2008). In other words, the idea of curriculum has been differentiated across a wide range of meanings. One basic view is the curriculum is "what is taught" (Squires, 1990). A narrow view holds that curriculum is "the body of courses" that presents knowledge, principles, values and skills that are the intended consequences of formal education (Levin, 1981). The boarded view holds that "the curriculum will have to be conceived as the name for the total active life of each person" (Taylor, 1950, p. 220).

It is difficult to give a definition for curriculum development, because it will always be affected very strongly by context where it takes place. There is a suggestion that something continuous is happening, maybe over a long time, although it is equally valid for short courses. We can think of curriculum development as a continuous process, which is relevant to the situation where it takes place, and flexible, so we can adapt it over time. As in a race, there may be a finishing point, but if you work in curriculum development, you will probably find out that the work does not end at a particular moment. Ornstein \& Hunkins $(2009$, p. 15) contend that curriculum development encompasses how a curriculum is planned, implemented and evaluated, as well as what people, processes and procedures are involved in. They suggested that although curriculum development models are technically useful, they often overlook the human aspect such as the personal attitudes, feelings and values involved in curriculum making. Anyway, curriculum development describes all the ways in which training or teaching organizations plan and guide learning. This learning can take place in groups or with individual learners. It can take place in an institutional setting like a school, college or training center. It is central to the learning process (Rogers \& Taylor, 1988). Generally, curriculum development is defined as planned, purposeful, progressive and systematic in the educational system. Every time there are changes or developments happening around the world, the school curricula are affected. There is a need to update them in order to address the society's needs. Curriculum development is only one of the fields in the domains within curriculum studies which provide methodic and mechanical skills in developing a curriculum or a plan. By curriculum planning process and regarding the stages, commonplaces or elements which are advocated by every curriculum development, a curriculum will be produced or developed. Therefore we should not be involved in a "displacement fallacy" and make a general misconception, to mistake one field for another, a fallacy which is widespread (Marzooghi, 2015, p. 8).

Briefly, it should be stated that the concept of curriculum is open to discussion in three general terms, "as a science", "as a process", and "as a product". As a science, the curriculum could be defined in two ways. In a brief definition, the curriculum as a science, study the "curriculum phenomenon". In a more general term and description, the curriculum science studies the history, theories, approaches, models, systems, dimensions, elements, types, designing, engineering, implementation, evaluation, changes, challenges, research development, current and future expansions of "curriculum phenomenon". Of course, this is a definition of curriculum science, but the definition should not be limited to a traditional or positivistic one because we should go beyond such perspective and paradigm.

The curriculum concept as a "process" regards the understanding and consideration of curriculum concept as "curriculum development". From this point of view, curriculum development is a "process" in which various activities such as goal determination, need assessment, content selection, and designing of teaching-learning strategies, evaluation and so on, are used in the developing and implementation of a curriculum. In other words, the ultimate "product" of the curriculum development, is the production of a "plan" or a "learning program". A design or program is the base and a guideline for the work of schools, teachers, and students. Additionally, it must be said that in the process of curriculum development "elements" or "commonplaces" of curriculum that should be regarded in the process, there is no agreement between the curriculum scholars so that these elements are counted from three to over more than ten ones.

The concept of the curriculum "as a product" or "a program" generally could not be defined due to its vast abundance. In other words, the curriculum is not a "type" but it has many "types" itself, and in a comprehensive explanation, there is no general definition for it. For example, it is actually impossible to represent a definition that includes all the intended, implemented, learned, implicit, hidden, omitted, sterilized, neglected, and empty curricula. Since for example, it could not be said that a curriculum includes "what is taught" and "what is not", "what is implicitly taught" and "what is explicit", what is unintentionally "omitted", what is intentionally "omitted", and "what that exists", representing such a definition is logically meaningless and impossible. The definition must be comprehensive and firm, therefore, whenever we want to define a curriculum, we must consider "the type" of curriculum that we have at hand. As mentioned before, the curriculum term is not a type with a perfect definition, but includes types itself which must be included in each one's definition. 


\section{Results}

The important point is that no serious research has been done by the curriculum scholars in order to classify the "types of the curriculum", but some efforts have taken place in attending to the classification of "curriculum definitions". In this regard, Portelli (1987) had gathered a large number of various curriculum definitions, from which he drew the conclusion that the definitions could be classified into three different groups based on the curriculum "as a content", "as a plan", and "as experiences". Kliebard (1972) preferred to classify curriculum definition based on metaphors. He proposes three different metaphors namely the curriculum "as a production", "as a growth", and "as a journey". Of course, there are other metaphors that can be used such as "play", "surfing" and "emergentness" metaphors, and so on, which are not considered by him.

Additionally, various types of curriculum were mentioned by scholars such as explicit, implicit, null (Eisner, 2002, pp. 87-99), explicit, hidden and null (Eisner, 1985), ideal and actual (Marsh, 1992, p. 3), unwritten (Blumberg \& Blumberg, 1994), society-centered, student-centered, knowledge-centered, eclectic curricula (Longstreet \& Shane, 1993), hidden curriculum with universalistic and particularistic aspects (Lynch, 1989), planned, taught, learned and assessed curricula (Sergiovanni \& Starrat, 2007, pp. 126-127), disciplinary, inter-disciplinary, multi-disciplinary (Glickman et al., 2007, pp. 380-386), transmission, transactional and transformational (Glickman et al., 2007, p. 387), global-spaced, localized, localized, electronic (Marzooghi, 2013, pp. 124-150), clandestine, big, embodied, mandatory, exiled, homeschool, ecological (Kridel, 2010), community-service, inclusive, fused, multidisciplinary, mindless, project-based, problem-based, postsecondary, unschooling (Pinar et al., 1996), emancipatory curriculum (Apple et al., 2001, p. 132), systematic, existentialist, radical, pragmatic and deliberative (Null, 2001), intended hidden, omitted hidden, distorted hidden, sterilized hidden, real implicit, distorted, neglected, sterilized, correspondence implicit, resistance implicit, resistive curricula (Marzooghi, 2015).

Each of the curriculum scholars had their own opinion on curriculum classification based on his/ her point of view, need, and his/ her theoretical platform. Additionally, the definition and meaning of some curricula which had similar titles are not the same. From this perspective, it could be said that moreover to the "definition controversy", "theories controversy", "curriculum commonplaces controversy" and "typology controversy", "classification controversy" is also exist. As mentioned before, the curriculum is not a "type", but has various "types" itself. In order to further clarify the curriculum definitions and determine boundaries and differences between them, it is required to "categorize" curriculum types, although based on scholars notions, several methods of classification could be applied.

Therefore in this regard, fist the categories must be determined and then each classification should be defined based on the general and shared characteristics between the curricula located in that category. Second, each of the curricula embedded within each classification should be defined separately. But the important point is that in many occasions despite the shared meaning, there are only terminological and verbal differences in using the tittles. In other words, several terms were used for the same type of curriculum, which are placed in each of the 16 categories during the explanation on all curricula or curriculum typology process.

Table 1. Table title (this is an example of table 1)

\begin{tabular}{|c|c|c|}
\hline No & Category & Types \\
\hline 1 & Theoretical-oriented & $\begin{array}{l}\text { Behavioristic, cognitivist, humanistic, constructivist, democratic, community-service, descriptive, } \\
\text { eclectic, inclusive, inert, spiritual, modernistic, post-modernistic, post-formal, monoculture, } \\
\text { multicultural, normative, mono-realistic, pluralistic, progressive, scientific, society-centered, } \\
\text { student-centered, subject-centered, transformative, trans active, transmission, transpersonal, } \\
\text { transcendental, developmental, deliberative, service-learning, positivistic, emancipatory }\end{array}$ \\
\hline 2 & $\begin{array}{l}\text { Social-oriented and } \\
\text { curriculum-development } \\
\text { system }\end{array}$ & $\begin{array}{l}\text { Place-based, school-based, space-based, in content, site-based, centralized, semi-centralized, } \\
\text { decentralized, institutional, adapted, contact, cross-cultural, localized, globalized, localized, } \\
\text { internationalized, national, local, societal, traditional, big, in- between, state-mandated }\end{array}$ \\
\hline 3 & $\begin{array}{l}\text { Racial-oriented and } \\
\text { gender-oriented }\end{array}$ & Feministic-based, male-oriented, sex-based, differentiated, segregated, race-based, ethnocentric \\
\hline 4 & $\begin{array}{l}\text { Subject-centered and learning } \\
\text { levels }\end{array}$ & $\begin{array}{l}\text { Scientific broad-field, knowledge-based, disciplinary, inter-disciplinary, multi-disciplinary, } \\
\text { trans-disciplinary, integrated, fused, enabled, multi-vocational, professional, separate subject-matter, } \\
\text { skill-based, technical, core, vocational, linear, helix, spiral, spider web, hierarchical, staircase, } \\
\text { sequenced, balanced, parallel }\end{array}$ \\
\hline 5 & Methodic and process-based & Activity-based, action-based, inquiry-based, problem-based, innovative, collaborative \\
\hline 6 & Schooling level & $\begin{array}{l}\text { Pre-school, elementary, secondary, postsecondary, higher education, early childhood, further, } \\
\text { complementary }\end{array}$ \\
\hline
\end{tabular}




\begin{tabular}{lll}
\hline 7 & Formal/Intended & $\begin{array}{l}\text { Approved, common, explicit, generic, ideal, phantom, overt, planned, prescriptive, public, visible, } \\
\text { exiled, written, internal }\end{array}$ \\
\hline 8 & $\begin{array}{l}\text { Implemented and based on } \\
\text { teacher contribution }\end{array}$ & $\begin{array}{l}\text { Operational, actual, applied, adopted, delivered, instructional, thought, experiential, live, } \\
\text { teacher-based, teacher-proof, adapted, enacted }\end{array}$ \\
\hline 9 & Learned and learner-based & Achieved, experienced, narrative, personalized, student-oriented, student-proof, individualized \\
\hline 10 & Evaluation-oriented & Assessed, evaluated, tested, measured, appraised, outcome-based, unmeasured \\
\hline 11 & Implicit & $\begin{array}{l}\text { Tacit, concomitant, correspondence, embodied, ignored, invisible, real implicit, unintended, } \\
\text { unintended-implicit, adjusted, adaptive, thematic, overuse, mindless, informal }\end{array}$ \\
\hline 13 & Hidden & $\begin{array}{l}\text { Unwritten, unspoken, unstudied, covert, neglected-hidden, sterilized-hidden, resistance, clandestine, } \\
\text { universalistic, particularistic, pre-planned hidden }\end{array}$ \\
\hline 14 & Emergent & $\begin{array}{l}\text { Un- schooling, homeschool, extra, extracurricular, media, outside } \\
\text { Incidental, expressive, exposed, bouncy, un-preplanned }\end{array}$ \\
\hline 15 & Null & $\begin{array}{l}\text { Absent, empty, in-absentia, distorted, intended-distorted, intended-null, intended-omitted, } \\
\text { intended-sterilized, lost, missed, neglected, omitted, omitted-hidden, intended sterilized, unintended } \\
\text { distorted, unintended omitted, unintended null, unintended sterilized, intended neglected }\end{array}$ \\
\hline 16 & Digital & $\begin{array}{l}\text { Electronic, web-based, online, offline, internet-based, intranet-based, computer-based, digital implicit, } \\
\text { digital hidden, digital omitted, digital sterilized, digital neglected, digital distorted }\end{array}$ \\
\hline
\end{tabular}

\section{Discussion}

As observed in the table (1), more than 215 types of curricula were classified into 16 categories. The basis of classification was the "conceptual" and "terminological" similarity between curriculum types in meaning, and the general definition shared between them. In other words, in each category, the curricula are placed which have a meaningful match, although some are only verbally different. Moreover, in some cases, although there is only a verbal difference, it is also noticeable. In any way, the classification logic is the case of focusing on overall, general, or shared meanings between the curricula, even if their similarities are simply regarded as a "conceptual", "terminological", "verbal" or "vocabulary" aspect.

For example, in the "theoretical category", the curricula were placed where were devoted to "various philosophical and theoretical" point of views. The range of these theoretical orientations is much extended and includes many approaches, educative and theoretical philosophies which are in some cases contradictory (Table 1). The detailed description of various curricula is noted in the classification and the rest of the 16 categories require a prolonged and separate analysis which would not be available in this article. Accordingly, each of the 16 groups includes various curricula such as racial and gender-oriented, subject-centered and learning levels, methodic and process-based, schooling level, formal/intended, implemented and based on teacher contribution, learned and learner-based, implicit, hidden, non-formal, emergent, null, and digital, and each of those categories could be separately studied and analyzed as an important research for later time. Anyhow, the capacity to conduct such a research is only prepared by this innovative research effort, which is an important one, but needed more extended study.

\section{References}

Bilbao, P. P., Luncido, P. I., Lringan, T. C., \& Javier, R. B. (2008). Curriculum development. Philippines: Lorimar Publishing, INC.

Blumberg, A., \& Blumberg, P. (1994). The unwritten curriculum. Thousand Oaks, CA: Crowin.

Bobbitt, F. (1918). The curriculum. Boston: Houghton Mifflin.

Eisner, E. (1985). The educational imagination: the design and evaluation of school programs. New York: Macmillan.

Eisner, E. (2002). The educational imagination: the design and evaluation of school programs. Columbus, Ohio: Merrill Prentice Hall.

Gickman, C. D. (2007). Supervision and instructional leadership: A developmental approach. Boston, New York: Pearson.

Jackson, P. (1992). Conceptions of curriculum and curriculum specialist. In P. Jackson (Ed.), Handbook of research on curriculum (pp. 3-40). New York: Macmillan.

Kliebard, H. (1972). Metaphorical roots of curriculum design. Teacher College Record, 72(3), 403-405.

Kliebard, H. (1992). Forging the American curriculum. New York: Routledge.

Kridel, C. (2010). Encyclopedia of curriculum studies. Los Angeles, London, New York: SAGE. 
http://dx.doi.org/10.4135/9781412958806

Levine, A. (1981). Handbook on undergraduate curriculum. San Francisco: Jossey-Bass.

Longstreet, W. S., \& Shane, H. G. (1993). Curriculum for new millennium. Boston: Allyn and Bacon.

Lynch, K. (1989). Hidden curriculum. Trowbridge, Wiltshire: Redwood Burn.

Marsh, C. (1992). Key concepts for understanding the curriculum. London, England: Flamer.

Marzooghi, R. (2004). Theories, methods, and political education curriculum in the general education system of Iran (in Persian). Shiraz, Iran: Meshkat publication.

Marzooghi, R. (2012). Foundation, principles and emerging development in the contemporary education (in Persian). Shiraz, Iran: Taghte Jamshid Publication.

Marzooghi, R. (2015). Curriculum sciences: new and future development. Tehran, Iran: Avaye Noor Publication.

McMillian, J., \& Schumacher, S. (2001). Research in education: a conceptual introduction (5th ed.). New York: Harpers Collin College Publisher.

Miles, M. B., \& Huberman, A. M. (1994). Qualitative data analysis: an Expanded source book. Thousand Oaks: SAGE Publications.

Null, W. (2011). Curriculum: from theory to practice. Lanbam, Boulder, New York, Toronto, Plymouth, UK: Rowman \& Littlefield Publishers, INC.

Oliva, P. (1977). The curriculum. Theoretical dimensions. New York: London.

Ornstein, A. C., \& Hunkins, F. P. (2009). Curriculum foundations, principles, and issues (5th ed.). Boston: Allyn and Bacon.

Palmer, J. (2001). Modern thinkers on education: from Piaget to the present. London: Routledge.

Rogerss, A., \& Taylor, P. (1988). Participatory curriculum development in agricultural education. A training guide. Rome: FAO.

Sandelowski, M. (2000). Whatever happened to qualitative description? Research Nurse Health, 23, 334-340.

Squires, A. (1990). First degree: the undergraduate curriculum. ERIC documented 326168.

Taylor, H. (1950). Essays in teaching. New York: Harper.

Walker, D. F. (2003). Fundamentals of the curriculum: passion \& professionalism (2nd ed.). London and New Jersey: LEA/ Publishers.

Willson, L. O. (2006). Curriculum course packets ED 7218726.

\section{Copyrights}

Copyright for this article is retained by the author(s), with first publication rights granted to the journal.

This is an open-access article distributed under the terms and conditions of the Creative Commons Attribution license (http://creativecommons.org/licenses/by/4.0/). 